\title{
Development of software for calculating the parameters of coal- water slurry fuel
}

\author{
Anton Sinitsyn ${ }^{1, *}$, Irina Akhmetova ${ }^{2}$ and Ekaterina Filippova ${ }^{1}$ \\ ${ }^{1}$ Department of Heat and Gas and Water Supply, Vologda State University, Lenina str. 15, 160000, Russia \\ ${ }^{2}$ Kazan State Power Engineering University, Kazan, Russia
}

\begin{abstract}
The paper presents the developed software tool for calculating the combustion process. Computational studies were performed for coal-water slurry fuel. Using the developed program the calorimetric efficiency and environmental performance of CWS combustion in experimental and industrial installations can be calculated in automatic mode.
\end{abstract}

\section{Introduction}

Currently, there are many problems in the fuel and energy complex (FEC), one of which is the constant rise in prices for energy resources, including fuel oil and natural gas. The other problem is low efficiency of coal, as during grate firing up to $30 \%$ of the supplied volume remains unburned and goes to the dump. In results in high cost per unit of heat generated from traditional fuels.

A large number of scientists and specialists have worked and are working to increase the efficiency of the fuel and energy complex and its subsystems: A.I. Andryushchenko, V.M. Brodyansky, E.Ya. Sokolov, Yu.P. Melentiev, A.P. Merenkov, E.V. Sennova, V.A. Stennikov, M.N. Singer, K.N. Trubetskoy et al. Particularly noteworthy is the work [1], which allows us to draw conclusions about the prospects of fuel power industry and the possibility of using coal-water slurry fuels (CWS). The works of K. Sato, P. Andreussi, K. V. Thumbimuthu, etc. are the international studies related to the development of efficient combustion systems. These studies are devoted to both consideration of environmental advantages of coal liquid fuels and description of atomized combustion of coal-water slurry fuel in various devices [2-4].

In general, the issues of increasing the efficiency of heat supply sources, and, in particular, the processes of burning organic fuel, are relevant and were previously studied in [5-11].

The use of pulsating combustion of fuel in power plants, the creation of conditions for the complete combustion of the fuel-air mixture due to optimal geometric devices of the combustion space, etc. are the examples of increasing combustion efficiency. In [12], the impact of magnetic field on the completeness of combustion of gas-air mixtures was studied.

One of the solutions to these problems may be the creation and implementation of a new type of fuel, which will serve as an alternative to traditional types and will allow more efficient use of raw materials and reduce the cost of the generated heat. For these purposes coal-water slurry fuel (CWS) can be used, which is obtained by mixing finely ground coal or other carbon-containing raw materials with water or aqueous emulsion.

The tasks were set to study the efficiency of using coal-water slurry fuel as an alternative to traditional types of fuels, in particular coal, as well as to develop software for calculation the combustion process of coalwater slurry fuel. These works were performed as part of research work on the development of an effective CWS dispersion and homogenization system for the Amaltea LLC (Russia) at fuel preparation stage.

The obtained results, by analogy with [13], will make it possible to calculate the calorimetric efficiency and the environmental performance of CWS combustion in experimental and industrial installations using computeraided procedures.

The purpose of this study is to create a mathematical model and software for the automated calculation of parameters of combustion process of water-carbon fuel based on the existing techniques.

\section{Subject of study}

The subject of research is coal-water slurry fuel. As already mentioned, such type of fuel is obtained by mixing crushed coal (particle sizes are $<200 \mu \mathrm{m}$ ) with water or aqueous emulsion. Emulsions of fuel oil swabs or emulsions of organic origin are used to further increase the calorific value of CWS. The proportion of coal in the fuel composition is from 52 to $65 \%$, and the proportion of liquid component can be from 35 to $48 \%$.

The most common raw materials for CWS are:

1) Coals of most grades - brown, gas, long-flame, lean, anthracite;

2) Carbon-containing raw materials: pyrocarbon (carbon after thermal decomposition of tires and rubber

Corresponding author: sinitsyn.science@ mail.ru 


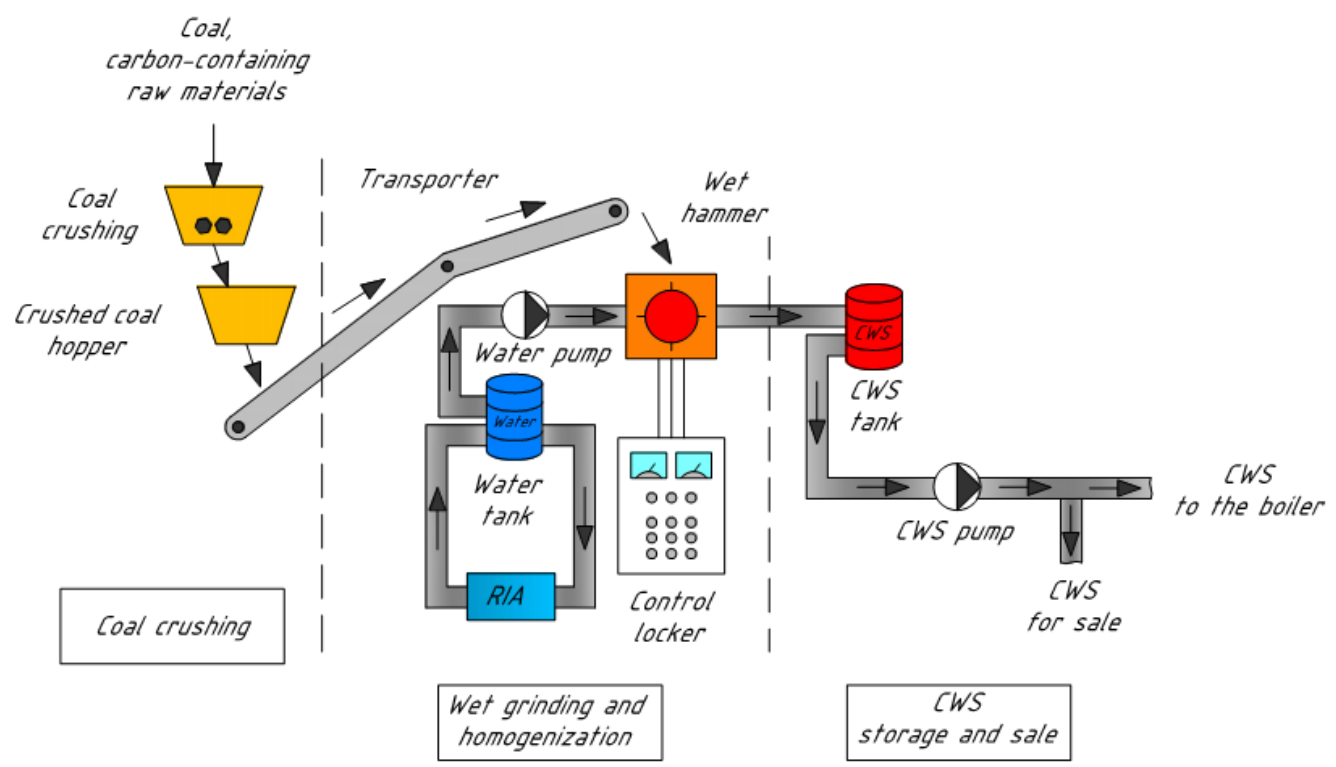

Fig. 1. The technology of preparation of coal-water slurry fuel (processes at Amaltea LLC are used as example).

under conditions of oxygen deficiency), petroleum coke (solid residue of the secondary processing of oil or oil products) and others;

3) Coal production waste (riddlings with fractions up to 1 - $6 \mathrm{~mm}$, usually disposed as waste).

Preparation of coal water fuel includes three stages (Fig. 1):

1) Crushing of coal (if the initial particle size of coal exceeds $12 \mathrm{~mm}$ );

2) Wet grinding (up to a fraction of $100-150$ microns);

3) Homogenization (which makes the obtained product uniform).

The prepared fuel passes quality control according to the following parameters:

1) Solids content (mass fraction of coal), which determines the calorific value of the final product and CWS viscosity;

2) Granular composition (dispersion), which depends on combustion method planned to be used at the facility;

3) Static stability, which determines the requirements for the technological regulations of fuel storage, the need for additional reagents or other measures;

4) Viscosity, which determines the requirements for pumping equipment and the quality of fuel atomization [13].

Typical characteristics of coal-water slurry fuel are presented in table 1 .
Table 1. Typical characteristics of coal-water slurry fuel

\begin{tabular}{|c|c|}
\hline Parameter & Value \\
\hline 1 & 2 \\
\hline $\begin{array}{l}\text { Mass fraction of solid } \\
\text { phase (coal) }\end{array}$ & $58-70 \%$ \\
\hline Grading & $\begin{array}{l}100 \% \text { fractions less than } 200 \\
\text { microns }\end{array}$ \\
\hline Density & about $1200 \mathrm{~kg} / \mathrm{m}^{3}$ \\
\hline Ash content of solid phase & $\begin{array}{l}5-50 \% \text { (depends on grade of } \\
\text { source coal) }\end{array}$ \\
\hline Net calorific value & $\begin{array}{c}2300-4300 \mathrm{kcal} / \mathrm{kg} \\
\text { (depends on grade of source coal) }\end{array}$ \\
\hline $\begin{array}{l}\text { Viscosity at a shear rate of } \\
81 \mathrm{~s}^{-1}\end{array}$ & no more than $1000 \mathrm{MPa} \cdot \mathrm{s}$ \\
\hline Flash point & $450-650{ }^{\circ} \mathrm{C}$ \\
\hline Combustion temperature & $950-1100^{\circ} \mathrm{C}$ \\
\hline Static stability & $\begin{array}{l}\text { - up to } 5 \text { - } 10 \text { days - without the } \\
\text { use of additives } \\
\text { - from } 10 \text { days - the use of } \\
\text { additives is possible } \\
\text { - from } 30 \text { days - with the use of } \\
\text { additives }\end{array}$ \\
\hline Freezing temperature & $0^{\circ} \mathrm{C}$ (without additives) \\
\hline
\end{tabular}

The other parameters (calorific value, ash content, sulfur content, etc.) depend on CWS parameters and characteristics of the source coal.

The main methods of burning such fuel are the following:

1) Autonomous flame combustion;

2) Fluidized bed combustion;

3) Burning together with other fuel.

In the first case, fuel is supplied under pressure through a spray nozzle into the combustion chamber. For this method, it is possible to implement an intermediate stage of partial gasification of CWS in order to supply generator gas - a mixture of carbon monoxide and hydrogen to the boiler. Gasification is carried out by 
converting the organic part of fuel into combustible gases during high-temperature heating with an oxidizing agent. The obtained gas, getting into the boiler furnace, increases the stability of CWS combustion (Fig. 2).

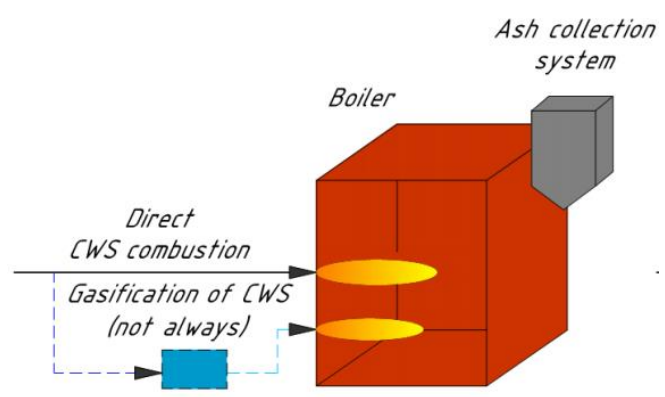

Fig. 2. Autonomous flame combustion of CWS.

The second method involves spraying fuel over a preheated layer of inert material, most often sand. Particles of CWS, falling on a fluidized bed, ignite almost instantly. Combustion using a fluidized bed can be carried out both directly in the boiler and in a special preheater (Fig. 3).

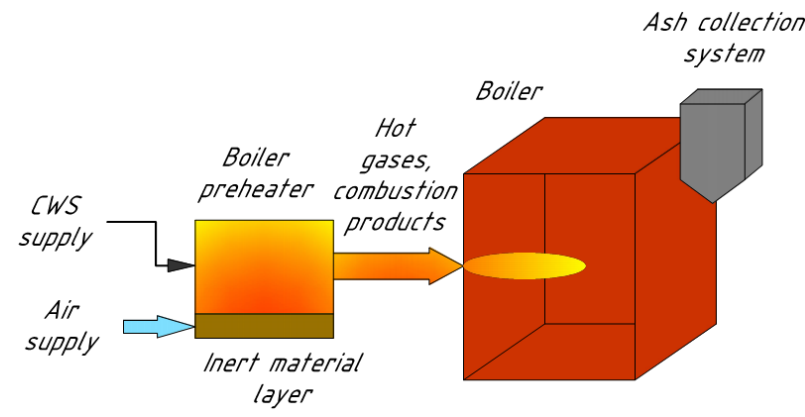

Fig. 3. Fluidized-bed combustion of CWS.

The third method involves the co-combustion of CWS with fuel already used at the heat source - coal, fuel oil or gas. Partial gasification of fuel can be also carried out here (Fig. 4).

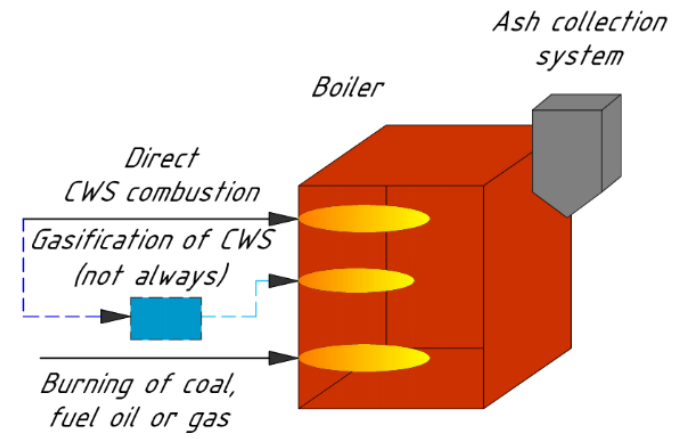

Fig. 4. Combustion of CWS together with other fuel.

\section{Mathematical model for calculation the combustion process of coal-water slurry fuel}

The study of efficiency of coal-water slurry fuel as an alternative to traditional types of fuels required to calculate the percentage composition of CWS and the amount of pollutants generated during the CWS combustion. To solve these problems, a program was created that allows calculating the parameters of combustion process of coal-water slurry fuel.

The physical model of process is shown in Fig. 1. Fuel of specific calorific value is supplied to the boiler at a certain temperature together with air of its own temperature. Heat released during their combustion is the available heat of the furnace space.In the work, the basic equations of the known methods will be used. [14,15].

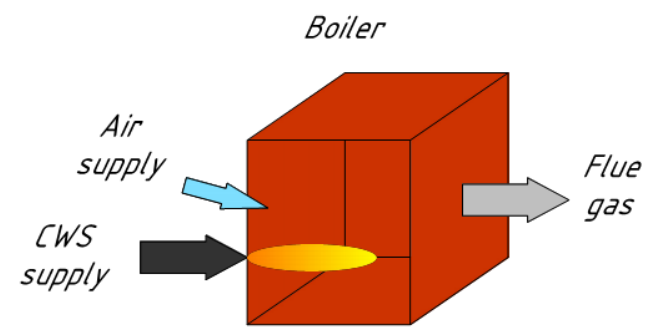

Fig. 5. Physical model of process.

To carry out the calculation, it is necessary to know the composition of burned fuel (the share of each component, its density and heat capacity), the temperature of fuel and air supplied to boiler, the calorific value of fuel, its density, the actual amount of air needed to burn the fuel, and the volumes of combustion products generated during fuel combustion.

The calorimetric combustion temperature is found from the heat balance equation of the furnace space (1), where the fuel is burned:

$$
Q_{C W S}+Q_{n}{ }^{r}+Q_{a}=I_{f g}, k J / k g,
$$

where $\mathrm{Q}_{\mathrm{Cws}}$ is the physical heat of fuel introduced into the furnace space, $\mathrm{kJ} / \mathrm{kg}$;

$\mathrm{Q}_{\mathrm{n}}{ }^{\mathrm{r}}$ is the net calorific value, $\mathrm{kJ} / \mathrm{kg}$;

$\mathrm{Q}_{\mathrm{a}}$ is the physical heat of air introduced into the furnace space, $\mathrm{kJ} / \mathrm{kg}$;

$\mathrm{I}_{\mathrm{fg}}$ is the flue gas enthalpy at calorimetric combustion temperature, $\mathrm{kJ} / \mathrm{kg}$.

The physical heat of fuel, the heat of its combustion and the physical heat of air in total form the available heat of the furnace space (2):

$$
Q_{C W S}+Q_{n}^{r}+Q_{a}=Q_{\text {fuel }}, \mathrm{kJ} / \mathrm{kg}
$$

The flue gas enthalpy is found by the formula (3):

$$
I_{f g}=\Sigma(c V)_{f g} \cdot t, k J / k g,
$$

where $\Sigma(\mathrm{cV})_{\mathrm{fg}}$ is the total volumetric heat capacity of all flue gases, $\mathrm{kJ} /\left(\mathrm{kg} \cdot{ }^{\circ} \mathrm{C}\right)$;

$\mathrm{t}$ is the combustion temperature, ${ }^{\circ} \mathrm{C}$.

Thus, this computation section consists of three stages:

1) Calculation of the amount of thermal energy transferred to the furnace space;

2) Calculation of the flue gas enthalpy; 


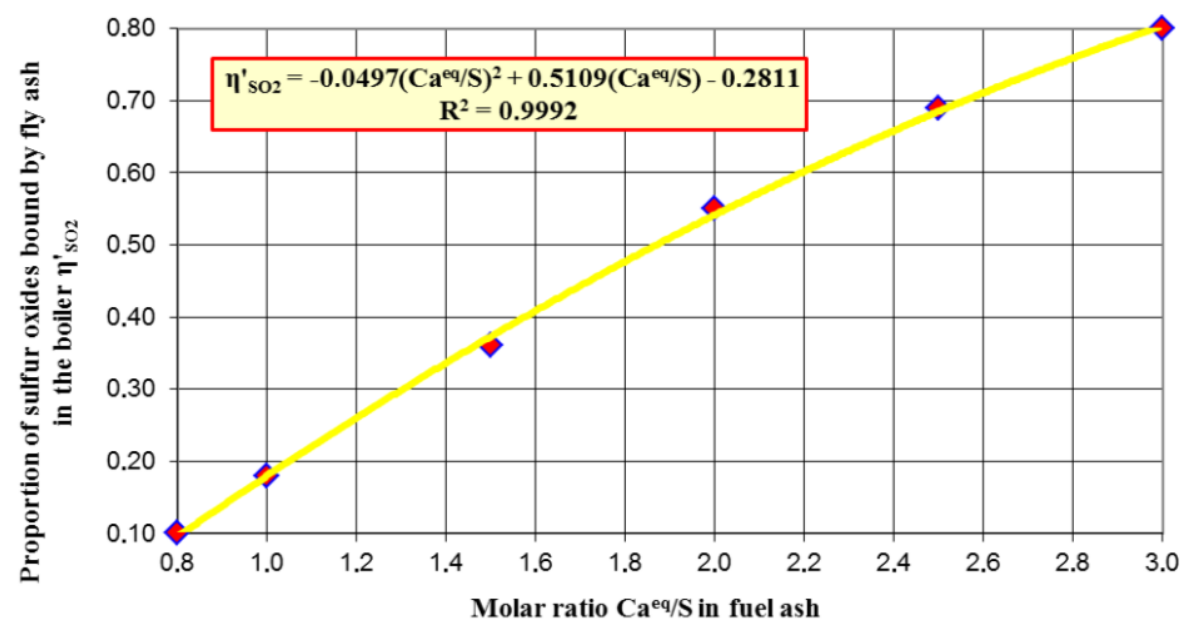

Fig. 6. Graphical representation and selection a formula for experimental data.

3) Checking the obtained value of the calorimetric temperature.

Thermal energy transferred to the combustion chamber consists of three components: heat from fuel, heat from air and heat of fuel combustion.

The thermal energy from fuel is calculated by the formula (4):

$$
Q_{C W S}=\frac{T_{\mathrm{CWS}} \cdot \Sigma\left(c_{i} V_{i} \rho_{i}\right)}{\rho_{W C S}}, \mathrm{~kJ} / \mathrm{kg},
$$

where $\mathrm{T}_{\mathrm{CWs}}$ is the fuel temperature, ${ }^{\circ} \mathrm{C}$;

$\mathrm{c}_{\mathrm{i}}$ is the heat capacity of the $\mathrm{i}$-th fuel component, $\mathrm{kJ} /\left(\mathrm{kg} \cdot{ }^{\circ} \mathrm{C}\right)$;

$\mathrm{V}_{\mathrm{i}}$ is the share of $\mathrm{i}$-th component in fuel composition;

$\rho_{i}$ is the density of the $\mathrm{i}$-th component, $\mathrm{kg} / \mathrm{m}^{3}$;

$\rho_{\text {Cws }}$ is the fuel density, $\mathrm{kg} / \mathrm{m}^{3}$.

The thermal energy from air is calculated by the formula (5):

$$
Q_{a}=T_{a} \cdot c_{a} \cdot V_{a} \cdot \rho_{a}, \mathrm{~kJ} / \mathrm{kg},
$$

where $\mathrm{T}_{\mathrm{a}}$ is the temperature of supplied air, ${ }^{\circ} \mathrm{C}$;

$\mathrm{c}_{\mathrm{a}}$ is the heat capacity of air, $\mathrm{kJ} /\left(\mathrm{kg} \cdot{ }^{\circ} \mathrm{C}\right)$;

$\mathrm{V}_{\mathrm{a}}$ is the actual volume of air required for burning 1 $\mathrm{kg}$ of fuel, $\mathrm{m}^{3} / \mathrm{kg}$;

$\rho_{\mathrm{a}}$ is the air density, $\mathrm{kg} / \mathrm{m}^{3}$.

The enthalpy of flue gases depends on two quantities - their total heat capacity and combustion temperature. But the heat capacity itself depends on temperature, so the enthalpy is calculated by the approximation method in the following sequence:

1) The initial temperatures $t_{1}$ and $t_{2}$ are set;

2) The volumetric heat capacity of components of flue gases at these temperatures are found;

3) The total heat capacity of all flue gases is found according to the formula (6):

$$
\begin{aligned}
& \Sigma(\mathrm{cV})_{f g}=(\mathrm{cV})_{\mathrm{RO} 2} \cdot V_{\mathrm{RO} 2}+(\mathrm{cV})_{\mathrm{H} 2 \mathrm{O}} \cdot \mathrm{V}_{\mathrm{H} 2 \mathrm{O}}+ \\
& +(\mathrm{cV})_{\mathrm{N} 2} \cdot V_{\mathrm{N} 2}, \mathrm{~kJ} /\left(\mathrm{kg}{ }^{\circ} \mathrm{C}\right),
\end{aligned}
$$

where $(\mathrm{cV})_{\mathrm{RO} 2},(\mathrm{cV})_{\mathrm{H} 2 \mathrm{O}}$ and $(\mathrm{cV})_{\mathrm{N} 2}$ are volumetric heat capacities of triatomic gases, water vapor and nitrogen vapor, respectively, $\mathrm{kJ} /\left(\mathrm{m}^{3} \cdot{ }^{\circ} \mathrm{C}\right)$;

$\mathrm{V}_{\mathrm{RO} 2}, \mathrm{~V}_{\mathrm{H} 2 \mathrm{O}}$ and $\mathrm{V}_{\mathrm{N} 2}$ are the volumes of triatomic gases, water vapor and nitrogen vapor, respectively, $\mathrm{m}^{3} / \mathrm{kg}$;

4) The enthalpy of flue gases is found by the formula (3).

The calorimetric combustion temperature $t_{k}$ will be calculated automatically using calculations for temperatures $t_{1}$ and $t_{2}$. Further, the volumetric heat capacities of flue gas components, their total heat capacity and enthalpy will be found for it.

The final step is to check the obtained calorimetric temperature according to the condition (7):

$$
\Delta=\frac{Q_{\text {fuel }}-\mathrm{I}_{\mathrm{fg}}}{Q_{\text {fuel }}} \cdot 100 \% \leq 3 \%
$$

\section{Numerical simulation results}

1) Processing of experimental data is performed in accordance with methods given in $[14,15]$. The developed program includes mathematical processing of data and its graphical representation. For example, Figs. 6 and 7 present relationship between emissions of sulfur oxides and molar ratio of $\mathrm{Caeq} / \mathrm{S}$, nitrogen oxides and thermal power;

2) Adaptation of method for calculation the calorimetric temperature previously used for gaseous fuels to calculate the CWS combustion temperature. The table of fuel components was completely updated, a formula showing relationship between heat capacity of mineral part of fuel and its temperature was developed (1):

$$
C^{A}=(0.17+T) \cdot 4.187, k J /\left(k g \cdot{ }^{\circ} \mathrm{C}\right),
$$

where $\mathrm{T}$ is the fuel temperature, ${ }^{\circ} \mathrm{C}$. 


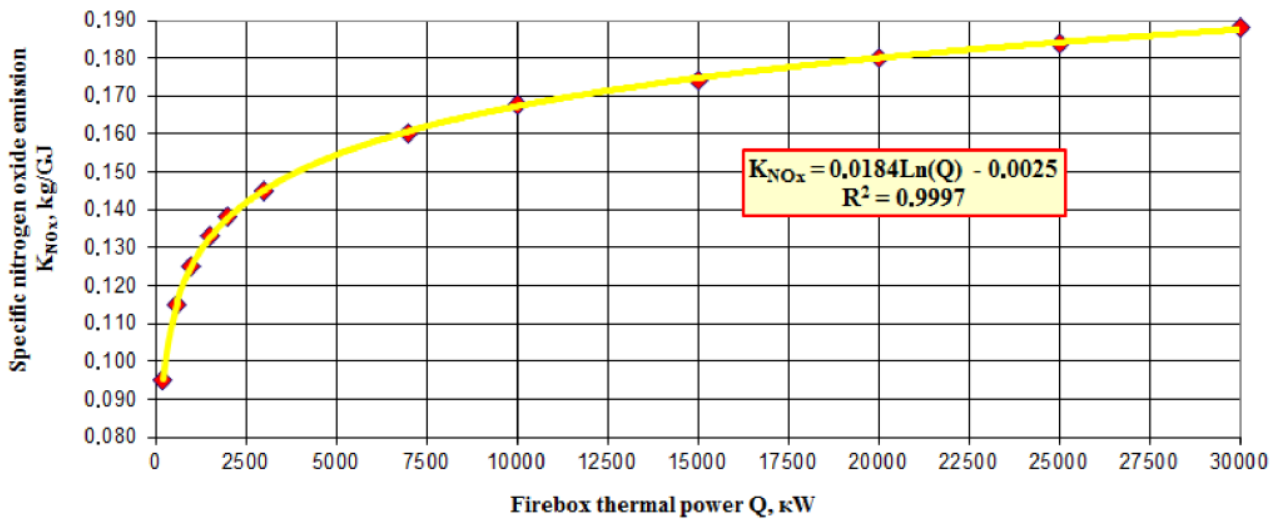

Fig. 7. Graphical representation and selection a formula for experimental data.

The program has some limitations of application. The calculations carried out using it will be correct for coal+water fuel without additives, which is burned by an autonomous flare method.

\section{Conclusions}

The following results were obtained during study of efficiency of coal-water slurry fuel usage as an alternative to traditional types of fuels:

1) In comparison with other types of fuels CWS usage has a number of significant technological, economic and environmental advantages. It will reduce the cost of a unit of generated heat energy, increase the efficiency of fuel resources use, make benefit from the products previously disposed as waste, and save environment. CWS is an environmentally friendly fuel in production and use and will not harm the environment during spills;

2) When developing a mathematical model, a unified methodology has been made up, which also includes experimental data presented as mathematical and graphical dependencies;

3) In the course of the study, a software tool was created that allows calculating the parameters of CWS combustion process.

\section{Acknowledgements}

The authors are grateful to Amaltea LLC for the information provided on the CWS production cycle.

\section{References}

[1] E. Sukhareva, A. Fedyukhin, O. Derevianko, M. Egorov, L. Mukhametova, I. Akhmetova, Optimization of combined heat and power plant operating mode by means of underutilized equipment mothball, IOP Conference Series: Earth and Environmental Science 288, 1, 012122 (2019).
[2] K.N. Trubetskoy, I.H. Nehoroshiy, Development of work on the use of suspensions in the energy sector of Russia, Thermal Engineering 1, 26-29 (1994).

[3] K. Sato, K. Okira, A. Baba, et. al, Study of spray combustion of CWM, Symposium on coal slurry fuels preparation and utilization, Pitsburgh Energy Technology Centre, 178-191.

[4] P.Andrussi, M. Graziadio, L. Tognotti et. al, Atomization of coal-water slurry fuels by pneumatic internal nozzle: part 1, Optimization and spray technology 3, 187-208 (1987).

[5] P. Andrussi, M. Graziadio, L. Tognotti et. al, Atomization of coal-water slurry fuels by pneumatic internal nozzle: part 2, Since and technology 13, 34-36 (1990).

[6] N. Sovetova, A. Sinitsyn, E. Tritenko, O. Derevianko, L. Mukhametova, A. Fedukhin, S. Makoev, A. Kalyutik, Regional management of district heating, IOP Conference Series: Earth and Environmental Science Collection of materials International Scientific and Practical Conference, Institute of Physics and IOP Publishing Limited (2019).

[7] A.A. Sinitsyn, Study of vibrational characteristics of the operation of boiler units, News of higher educational institutions. Instrument-making 7, 51 (2008).

[8] A.A. Sinitsyn, N.N. Boytsova, I.G. Akhmetova, S.O. Makoev, A. Asadpoori, O.A. Stepanov, N.V. Rydalina, E.O. Antonova, B.G. Aksenov, Study of operation of power-generating devices of gaseous fuels combustion, International Journal of Mechanical Engineering and Technology 10, 2, 1480-1490 (2019).

[9] A.A. Sinitsyn, The calculation of the characteristics and of the geometrical sizes of power devices, European Applied Sciences 4 (2013).

[10] E. Sukhareva, A. Fedyukhin, O. Derevianko, M. Egorov, L. Mukhametova, I. Akhmetova, Optimization of combined heat and power plant 
operating mode by means of underutilized equipment mothball, IOP Conference Series: Earth and Environmental Science 288, 1, 012122 (2019).

[11] I.A. Sultanguzin, E.V. Zhigulina, Y.V. Yavorovsky, I.D. Kalyakin, A.V. Govorin, A.V. Fedyukhin, A.A. Krolin, S.V. Guzhov, O. Derevianko, L. Mukhametova, Development strategy of the energy supply system for MPEI campus blocks based on green building, IOP Conference Series: Earth and Environmental Science 288, 1, 012071 (2019).

[12] A.A. Sinitsyn, D. Rusakov. V.V. Izrantsev, S.A. Kravchenko, G.A. Konrashkova, Investigation of gas fuel combustion efficiency at magnetic field treatment, IOP Conference Series: Earth and Environmental Science Proceedings of the Conference the international scientific conference Efficient waste treatment - 2018, EWT-2018, 012082 (2019).

[13] E.N. Filippova, A.A. Sinitsyn, Development of a software tool for calculating the combustion process of coal-water slurry fuel, Intellectual Information Technologies and Intelligent Business, INFOS-2019 materials of the tenth international scientific and technical conference (2019).

[14] Methodology for determining emissions of pollutants into the atmosphere when burning fuel in boilers with a capacity of less than 20 Gcal per hour (The State Committee for Environmental Protection 09.07.1999, Intr. 01.01.2000, Moscow, 76, 1999).

[15] Methodology for calculating emissions of pollutants during combustion of coal-water slurry fuel $(6,1990)$. 